tumour pressing on the pons; while the paralysis of separate branches of the third and of the fourth nerve was com. patible with a lesion involving them as they pass through the dura mater. Neither of these views, however, accounted for the clonic spasm of the upper lid and internal rectus, while it was not likely that a growth of the base of the skull large enough to cause such intense general symptoms would leave the internal and inferior recti and the nerves to the pupils intact. When the ataxy, barely observable at first, became fully developed the diagnosis of disease of the corpora quadrigemina became more probable. The marked interference with vision in this case is unusual, as in most cases such loss has been slight or very late in appearing. It cannot in this case bave been due to implication of the optic thalamus or optic radiations, for it involved firstly and chiefly the left eye There was never any hemianopia. It is possible that the optic neuritis may have caused it; but, on the other hand, one frequently sees a similar amount of effusion with little or no loss of visual power. The escape of the cells and fibres controlling the pupils and the slight affection of the internal recti are points of interest in connexion with the statements of Hensen and Völckers as to the arrangement of centres on the floor of the aqueduct of Sylvius. These, the most anterior of the separate centres into which the nuclei of the third nerve are divisible, naturally escape injury from a lesion of the posterior corpora quadrigemina, while the centres for the upper lid, superior rectus, and external rectus are damaged. The paresis of the oral fibres of the left facial nerve and not of those to the orbicularis oculi is remarkable, considering the extent to which the third nucleus was injured. Mendel's view of the origin of the orbicular fibres of the seventh from the nucleus of the third would lead one to expect that these would suffer before the fibres to the mouth.

\section{GENERAL HOSPITAL, SINGAPORE.}

STRANGULATED DIAPHRAGMATIC HERNIA; NECROPSY; REMARKS.

(Under the care of Mr. A. J. MCCloskY.)

PATIENTS who are suffering from a diaphragmatic or phrenic hernia do not often reach adult age; the large majority of c ongenital hernias of the kind described were found when necropsies were being made on children. The various ways in which they form are as follows: (1) as a consequence of weakening of the diaphragm in some part, permitting of the protrusion of some of the abdominal contents into the chest ; (2) protrusion through a congenital opening in the diaphragm ; (3) through one of the natural apertures; and (4) through an opening which has formed as the immediate or remote result of a wound or laceration of muscle. The protrusion is usually on the left side of the body, the presence of the liver being sufficient as a rule to protect the right side. We have, however, published in THE LANCET a case of hernia on the right side, and mentioned other by Dr. Cornell, Dr. Hillier, and Dr. Murchison. The signs presented on the side of the chest into which the hernia has escaped are much like those of pnenmothorax and may be mistaken for it ; sometimes there is dulness on percussion in consequence of effusion or the presence of some of the solid viscera.

A woman aged twenty-two years was bronght to the hospital on Jaly 27th, 1894, complaining of vomiting, inability to swallow even liquids, and pain in the left side of the chest and back. The duration of her illness was only two days. She was the mother of two children, the last one being born six years ago. Her bowels were constipated. She had complete cesophageal obstruction, not being able to swallow even liquids. Liquids simply passed down the osophagus for a certain distance and then welled up without any effort on the part of the patient. She was a well-nourished subject, and had always enjoyed good health. There was no history of injury, and the patient could assign no cause for her illness. She bore an anxious countenance, as of impending death; her body was cold and clammy, and the pulse rapid, small, and thready. The patient was in such a desperate condition-"doubled up," restless, and tossing about on the cot-that a thorough physical examination was almost impossible. She rapidly sank and died six hours after admission into hospital. At the necropsy a diaphragmatic hernia was discovered

1 The LaNCET, May 16th, 1891 : case described by Dr. W. A. Hollis. at the most common site for such hernix-viz., on the left side. The herniated organs consisted of the stomach, the first part of the duodenum, omentum, spleen, and a few coils of the small intestine. The orifice was situated on the left side of the diaphragm close to its lateral posterior attachments to the ligamenta arcuata; it was circular in shape, smooth-edged, and of such a size as to admit the passage of five fingers. The stomach was "doubled up" upon itself, the greater curvature being uppermost in the left pleural cavity, and looking externally ; while that portion of the stomach immediately adjacent to the cardiac end, between the cesophageal opening and hernial orifice, could be seen, tense and shining like a bladder, protrading on the abdominal side of the diaphragm. The pylorus with the first part of the dnodenum was low down close to the orifice; the lesser curvature was directed inwards. The spleen lay behind and external to the stomach, against the plenral surface of the diaphragm, while immediately within the orifice were a few coils of the small intestine. The stomach was considerably dilated and presented numerous hæmorrhagic spots on its peritoneal surface; it contained a large quantity of dark-red bloody fluid, with partially digested food substance and shreds of mucus. The mucous membrane was acutely congested and eroded at parts, but not gangrenous. The heart was displaced considerably to the right, not extending to the left beyond the left lateral border of the sternum. The left lung was totally collapsed and pushed upwards against the clavicle, occupying only the supra- and infra-clavicular regions. The bowels were practically empty, the lumen contracted, and the walls atrophied; the mucous membrane presented a normal appearance.

Remarks by Mr. MCCLoskY.-I am of opinion that the orifice in the diaphragm was a congenital malformation because of its situation, its smooth and even margin, its circular shape, absence of any adhesions, and absence of any history of injury or signs of any fracture of ribs.

\section{Aftlexital Sortetitis.}

\section{CLINICAL SOCIETY OF LONDON.}

Abdominal Section for Intestinal Obstruction caused by Volur. lus of the Sigmoid Flexure - Early Erasion in Inflamma. tion of the Sacro-itiac Joint.-Orohotomy for Enlargement of Prostate.-Large Intra-thoracic Cystic Goitre causing Dyspncea and treated by Operation.

AN ordinary meeting of this society was held on April 26th, Mr. Langton, Acting President, being in the chair.

Dr. LUCAS BENHAM and Mr. SILCOCK related a case of Acute Intestinal Obstruction due to Volvalus of the Sigmoid Flezure. The patient was a female aged fifty-six years who had been affected with chronic mania and partial dementia for more than twenty years as the result of sunstroke in India some time before. She suffered from habitual constipation, which required the administration of simple aperients. She was thin, spare, and somewhat cachectic looking, but usually in fair health. The illness commenced with constipation, which was not relieved by the usual aperients. Sick. ness followed and became frequent and violent, the vomited matter containing some "coffee grounds" material, but was not stercoraceous. She was first seen two days after the earliest symptoms appeared, and by that time the abdomen was greatly distended, vomiting occurring after every attempt to swallow. No obstruction could be felt per rectum, and no relief conld be obtained by copious enemata \&c. On the following day, therefore, the abdomen was opened, under chloroform, and the whole of the colon was found enormously distended, the seat of obstruction being, as was anticipated, in the sigmoid flexure, where the intestine was twisted a half-turn on itself, forming a volvulus. This was reduced. There was no peritonitis. The wound was closed and dressed antiseptically. There was immediate and great relief from the operation. No sickness or distension of the abdomen followed. A large quantity of fæces cume away naturally. Slight pyrexia ensued, which lasted for ten days, but there was little other constitutional disturbance except a very dry brown tongue, which Dr. Benham was disposed to ascribe to the iodoform with which the wound was dressed. The last stitches were removed ten days after the operation, and the wound had completely healed a few days later. In a month from the date of the operation the patient was up and 